\title{
Global Ionospheric Structure Imaged by FORMOSAT-3/COSMIC: Early Results
}

\author{
Chien-Hung Lin ${ }^{1, *}$, Jann-Yenq Liu ${ }^{2}$, Chun-Chieh Hsiao ${ }^{3,4}$, Chao-Han Liu ${ }^{5}$, Chio-Zong Cheng ${ }^{1}$, \\ Po-Ya Chang ${ }^{2}$, Ho-Fang Tsai ${ }^{6}$, Tzu-Wei Fang ${ }^{2,7}$, Chia-Hung Chen ${ }^{2}$, and Mei-Lan $\mathrm{Hsu}^{2}$ \\ ${ }^{1}$ Plasma and Space Science Center, National Cheng-Kung University, Tainan, Taiwan, ROC \\ ${ }^{2}$ Institute of Space Science, National Central University, Chung-Li, Taiwan, ROC \\ ${ }^{3}$ National Space Organization, Hsinchu, Taiwan, ROC \\ ${ }^{4}$ Institute of Microelectronics, National Cheng Kung University, Tainan, Taiwan, ROC \\ ${ }^{5}$ Academia Sinica, Taipei, Taiwan, ROC \\ ${ }^{6}$ Central Weather Bureau, Taipei, Taiwan, ROC \\ ${ }^{7}$ High Altitude Observatory, National Center for Atmospheric Research, Boulder, CO, USA
}

Received 27 April 2007, accepted 18 January 2008

\begin{abstract}
A new era of studying the ionospheric space weather effects has come after launch of the innovative satellite constellation, named as Formosa Satellite 3 or Constellation Observing System for Meteorology, Ionosphere, and Climate (abbreviated as FORMOSAT-3/COSMIC or F3/C in short), performing a radio occultation experiment capable of observing the global ionosphere three-dimensionally. This is the first time that a satellite constellation provides instantaneously both the lower and upper parts of the ionospheric electron density up to the satellite altitude. With more than 2500 soundings of the ionospheric vertical electron density profiles every day, ionospheric plasma structures over many continents and most of oceans, where ground-based observation is limited, are now observed continuously. Important ionospheric research topics, such as space weather effects to the ionosphere, variations of ionospheric plasma structure and dynamics produced by solar outputs, and atmosphere-ionosphere coupling processes, can be widely studied and modeled based on the three-dimensional ionospheric images constructed by the F3/C observations. After one year in orbit, a great amount of radio occultation soundings allow us to construct global ionospheric maps to study the ionospheric seasonal effects and atmosphere-ionosphere interactions. Taking advantage of the uniqueness of dense global coverage, the major physical mechanisms of the two studies are given. For study of the seasonal variation during solstice, electron density images of the mid- and low-latitude ionosphere show a clear north-to-south asymmetry which may be affected by the summer-to-winter neutral wind. Meanwhile a significant longitudinal variation at midnight is also seen in the solstitial season. Another interesting result is the four stronger equatorial ionization anomaly (EIA) regions located at different longitudes. This four-peaked EIA structure may result from upward propagating nonmigrating tides originated from troposphere. F3/C's observation of the daytime four-peaked structure provides an important evidence to support the proposed forming mechanism.
\end{abstract}

Key words: FORMOSA-3/COSMIC, Three-dimensional ionosphere images, Atmospheric tides

Citation: Lin, C. H., J. Y. Liu, C. C. Hsiao, C. H. Liu, C. Z. Cheng, P. Y. Chang, H. F. Tsai, T. W. Fang, C. H. Chen, and M. L. Hsu, 2009: Global ionospheric structure imaged by FORMOSAT-3/COSMIC: Early results. Terr. Atmos. Ocean. Sci., 20, 171-179, doi: 10.3319/TAO.2008.01.18.01(F3C)

\section{INTRODUCTION}

The ionosphere is highly dynamic, showing strong variability due to solar activity and atmospheric conditions. The vertical structure of the ionospheric plasma is of interest to ionosphere researchers, since the vertical electron density

\footnotetext{
* Corresponding author

E-mail: clin@pssc.ncku.edu.tw
}

distribution is determined by equilibrium between transport and photochemical processes, and varies sensitively when these two major drivers change. Understanding the relation between these physical processes and the associated electron density vertical distribution helps future modeling or prediction of the ionospheric structure under various atmospheric and solar conditions. In the past, obser- 
vations of the ionospheric vertical structure rely on both space-borne and ground-based ionospheric radars, such as ground-based ionosonde and topside sounders onboard satellite missions. Currently, there are about two hundred standard ionosondes routinely recording ionograms. Although sophisticated incoherent scatter radars (ISRs) have the ability to make measurements from the ground to the topside ionosphere where is inaccessible to ionosondes, they are rather limited in number to about 10 . Recently, the radio beacon, satellite-borne transmitter, of the global positioning system (GPS) has been used to derive the ionospheric total electron content (TEC). By applying an interpolation and/or a model smoothing on the derived data from thousands of ground-based GPS receivers, a global ionospheric map can be constructed for studying the horizontal TEC structure of the global ionosphere (e.g., Mannucci et al. 1998; Komjathy et al. 2005; Mendillo and Klobuchar 2006). The ground-based GPS-TEC observations, however, only provide two-dimensional ionospheric observations but not vertical electron density profiles. Although computerized tomographic reconstruction of the three-dimensional ionospheric structure can be achieved, it requires a dense GPS receiver network. The significant shortcoming of the existing ground-based observations is the limited coverage over oceanic areas and many of the continents such as Africa, Central and West Asia, and the Middle East. In the past, this shortcoming can only be redeemed by satellite observations partially, and it was difficult to quickly yield a three-dimensional (3-D) global coverage of ionospheric vertical profiles observations simultaneously. A multiple satellite mission capable of performing the 3-D ionospheric observation is then desirable and essential to meet the above needs.

A powerful technique of using signals to derive the vertical profiles is known as the atmospheric radio occultation (e.g., Hajj and Romans 1998; Schreiner et al. 1999; Hajj et al. 2000; Yunck 2002). The technique was first used by the Mariner missions in exploration of planetary atmosphere in 1960s (Fjeldbo et al. 1971). The radio occultation technique was not applied to the Earth's atmosphere observation until an experiment satellite called GPS/MET in 1995 (Rocken et al. 1997; Hajj and Romans 1998). Using a GPS receiver onboard a low-earth orbit (LEO) satellite to receive radio signal transmitted by GPS satellites at an altitude of $20200 \mathrm{~km}$, vertical distribution of the atmospheric/ionospheric parameters are derived. Following the successful GPS/MET experiment, similar satellite missions, such as CHAMP (Germany), SAC-C (Argentina), GRACE (two satellites, US and Germany), and IOX (US), were carried out. However, these missions are mainly solo-satellite missions which require more time to complete global observation coverage.

The Formosa Satellite 3 also named as Constellation Observing System for Meteorology, Ionosphere, and Cli- mate (abbreviated as FORMOSAT-3/COSMIC or F3/C in short), is a multiple-satellite constellation designed to monitor the weather and space weather with its major payload, radio occultation experiment (GOX) instruments that perform the radio occultation observation in both troposphere and the ionosphere. Each microsatellite also has a tri-band beacon (TBB) transmitter to perform ionospheric tomography and a tiny ionosphere photometer (TIP) to observe the nighttime ionospheric airglow emission. The six microsatellite constellation was launched into a circular low-Earth orbit from Vandenberg Air Force Base, California, at 0140 UTC 15 April 2006. The constellation was launched to the initial orbit at an altitude of $512 \mathrm{~km}$, and $72^{\circ}$ inclination angle. It will take totally about 16 months for constellation to reach the mission orbit at around $800 \mathrm{~km}$ altitude, $72^{\circ}$ inclination angle, and $30^{\circ}$ separation in longitude between each microsatellite (Cheng et al. 2006).

With the radio occultation observations, ionospheric vertical electron density profiles can be observed globally and expected to obtain at least 2500 observations daily. The dense and global distributed ionospheric vertical profile observations will potentially provide 3 -D ionosphere images to better understand the variations of quiet-time ionospheric structures and dynamics. This paper will focus on applications of the radio occultation observations performed by the GOX instrument and the preliminary scientific results of ionospheric studies. It is noted that observations during magnetically disturbed periods are excluded in the data bins. In section 2, the 3-D ionospheric images are utilized to study the ionospheric seasonal effects and interesting nighttime ionospheric structures. Section 3 presents recently discovered longitudinal structure of the low-latitude and equatorial ionosphere. The local time variation of the unique longitudinal structure is first unveiled by the $\mathrm{F} 3 / \mathrm{C}$ constellation (Lin et al. 2007a). We summarize the preliminary ionospheric results presented in this paper in the section 4 .

\section{THREE-DIMENSIONAL IONOSPHERIC IMAGES AND THE SEASONAL EFFECTS}

The ionosphere exhibits strong seasonal dependence in its plasma structure. The plasma distribution in the mid- and low-latitude F region is controlled by both photochemical and transport processes. Changes of the solar zenith angle affect the photoionization process of the ionosphere and the thermal pressure gradient of the neutral atmosphere. Thermal expansion of the neutral atmosphere occurs in the hemisphere with more sunlight and results in trans-equatorial neutral winds and changes of neutral composition. Changes of the neutral wind and composition affect both ionospheric transport and photochemical processes. Plasma transport is affected by changes of field-aligned plasma flows produced by neutral winds through neutral-ion collisions, and strength of the $\mathbf{E} \times \mathbf{B}$ drift resulted from changes of the ionospheric 
conductivity (e.g., Fesen et al. 1989; Rishbeth 1998; Scherliess and Fejer 1999; Kil et al. 2006).

To examine the global ionospheric seasonal effects, Fig. 1 shows the electron density profiles at various latitudes at 1200 (local noon) and 0000 (local midnight) LT (global constant local time) during July - August 2006, months close to the June solstice. Figure 1a shows locations of the occultation points collected in the two month period and the associated vertical electron density profiles are shown in Fig. 1b. From Fig. 1b, the peak altitudes are generally higher in the northern (summer) hemisphere, while the peak density is higher in the southern (winter) hemisphere at $1200 \mathrm{LT}$ (up- per panel of Fig. 1b). At midnight, 0000 LT (the lower panel of Fig. 1b), the peak altitudes are similar in both north and south, while the peak density is greater in the northern hemisphere. From Fig. 1b, the greatest peak density exists in the latitude range of $\pm 20 \sim 10^{\circ} \mathrm{N}$ magnetic latitudes. The latitude region is the well-known equatorial ionization anomaly (EIA) region, which is the most prominent feature of the low-latitude ionosphere. The EIA electron density structure observed by the $\mathrm{F} 3 / \mathrm{C}$ is the major topic of this paper.

The equatorial ionization anomaly is produced by the equatorial plasma fountain (Namba and Maeda 1939; Appelton 1946; Duncan 1960; Hanson and Moffett 1966; An-
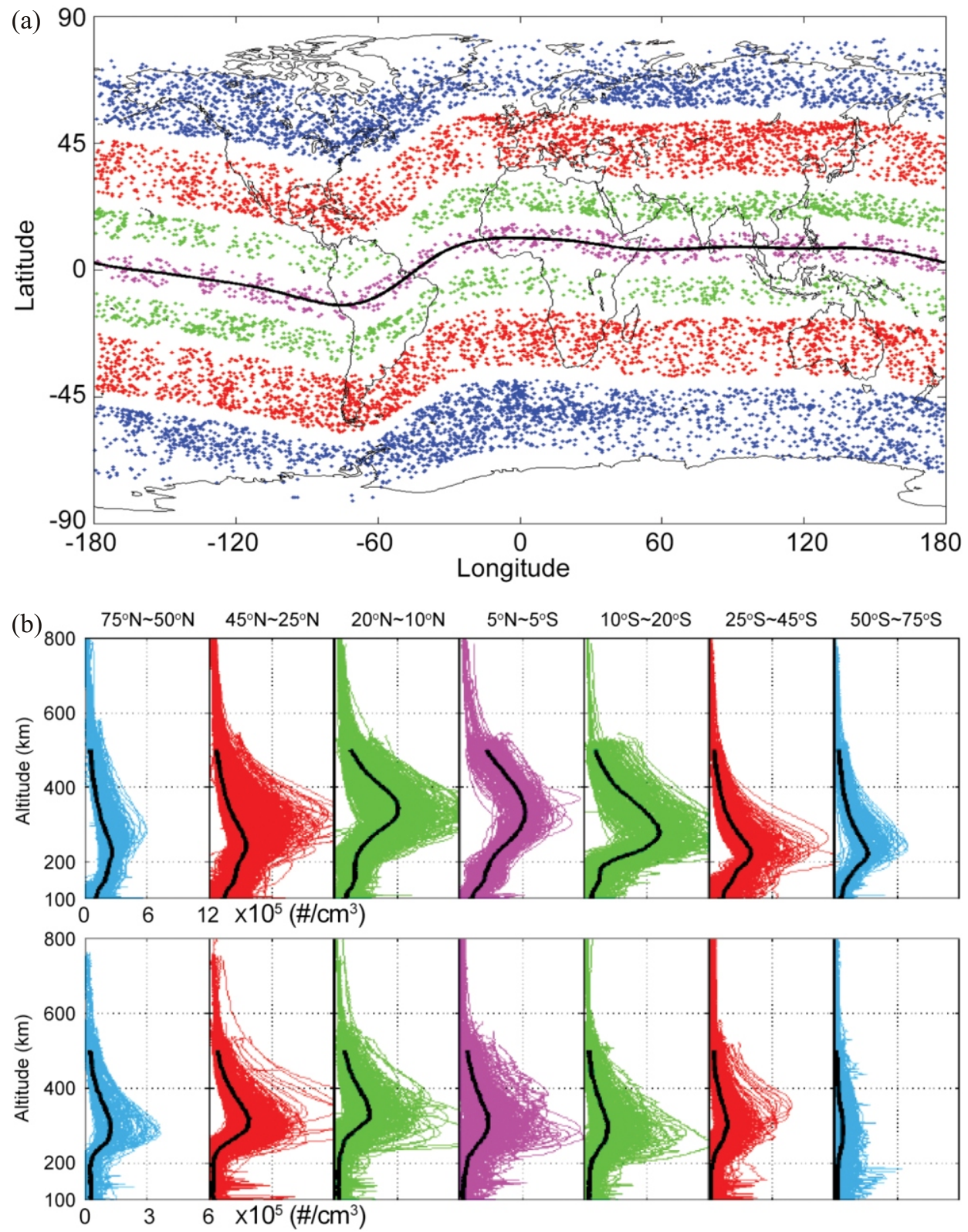

Fig. 1. (a) Locations of the occultation observations at various latitudes, and (b) electron density profiles at $1200 \mathrm{LT}$ (upper panel) and $0000 \mathrm{LT}$ (lower panel) at various latitudes during July - August 2006 . Observations at $\pm 50 \sim 70^{\circ} \mathrm{N}, \pm 45 \sim 25^{\circ} \mathrm{N}, \pm 20 \sim 10^{\circ} \mathrm{N}$, and $\pm 5^{\circ} \mathrm{N}$ are denoted by blue, red, green, and magenta colors, respectively. 
derson 1973; Balan and Bailey 1995; Balan et al. 1997; Rishbeth 2000). The equatorial plasma fountain results from a daytime eastward electric field that produces an upward $\mathbf{E}$ $\times \mathbf{B}$ drift which lifts the plasma to higher altitudes, from where it diffuses down along magnetic field lines to higher latitudes creating two ionization crests on both sides of the magnetic equator. Therefore, the strength and polarity of the zonal electric field would affect the equatorial plasma fountain and the EIA morphology. Although the equatorial fountain is the major driver for producing EIA, field-aligned plasma transport produced by neutral winds, and photochemical processes produced by neutral composition effects are also known to affect the EIA structure significantly, especially during the solstitial seasons.

Figure 2 shows the integrated electron content maps in a global constant local time of $1200 \mathrm{LT}$ at various altitude ranges from 150 - 200 to $400-450 \mathrm{~km}$. At 150 - $200 \mathrm{~km}$ altitude range, the brighter electron density bands, signature of the EIA, are located at around $\pm 20 \sim 30^{\circ} \mathrm{N}$ magnetic latitude. As the altitude increases, the two EIA bands move equatorward. Clear hemispheric asymmetry of the EIA bands is seen between $200-300 \mathrm{~km}$ altitudes with some longitudinal variations which may be due to differences in magnetic declination, $\mathbf{E} \times \mathbf{B}$ drift, and neutral winds in different longitudes. At $300-350 \mathrm{~km}$, the northern and the southern EIA bands between $60 \sim 120^{\circ} \mathrm{E}$ geographic longitudes are symmetric. The EIA becomes weaker above $350 \mathrm{~km}$ and the asymmetry between the north and the south are less discernible.

Similar to the Fig. 2, the global constant local time maps of $0000 \mathrm{LT}$ are shown in Fig. 3. The most interesting feature shown in Fig. 3 is the significant longitudinal variation seen above $250 \mathrm{~km}$ altitude. Between $-60 \sim 180^{\circ} \mathrm{E}$ geographic longitudes, stronger electron content is seen between 20 $60^{\circ} \mathrm{N}$ geographic latitudes, away from the magnetic equator. While between $-180 \sim-60^{\circ} \mathrm{E}$ geographic longitudes, the stronger electron content is seen around $-10 \sim 20^{\circ} \mathrm{N}$ geographic latitudes, next to the magnetic equator, except some scattered enhanced electron content seen around $30 \sim 60^{\circ} \mathrm{N}$ geographic latitudes between $-180 \sim-120^{\circ} \mathrm{E}$ geographic longitudes. It is interesting to see that there exist two electron content depletion areas located at Atlantic Ocean (-45
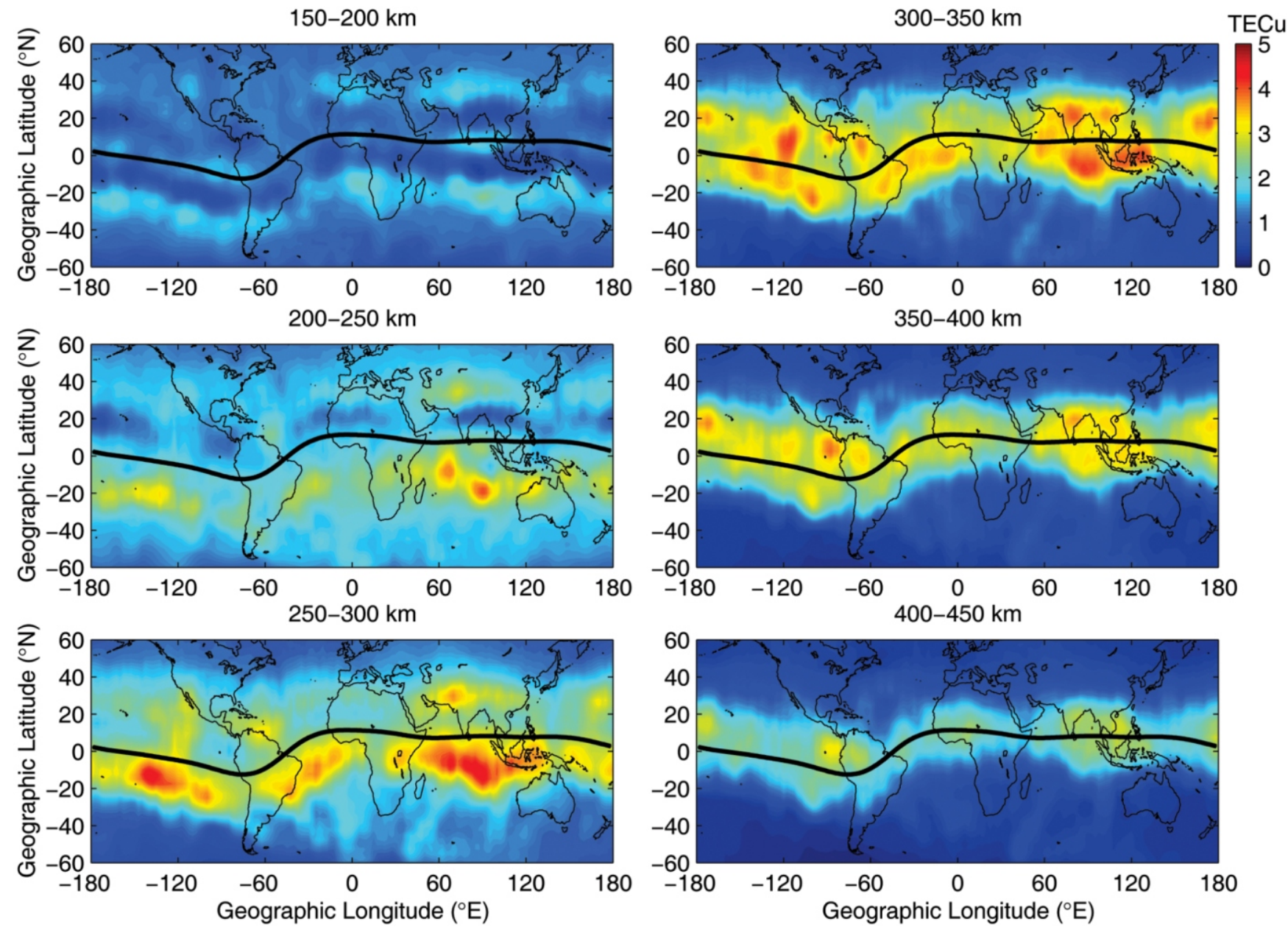

Fig. 2. Global ionosphere electron density maps at a constant local time, 1200 LT, at various altitudes observed by FORMOSAT-3/COSMIC during July - August 2006. Each subplot shows integrated electron content between the $50 \mathrm{~km}^{2}$ altitude interval. $1 \mathrm{TECu}^{\mathrm{T}} 10^{16}$ electron $\mathrm{m}^{-2}$. 

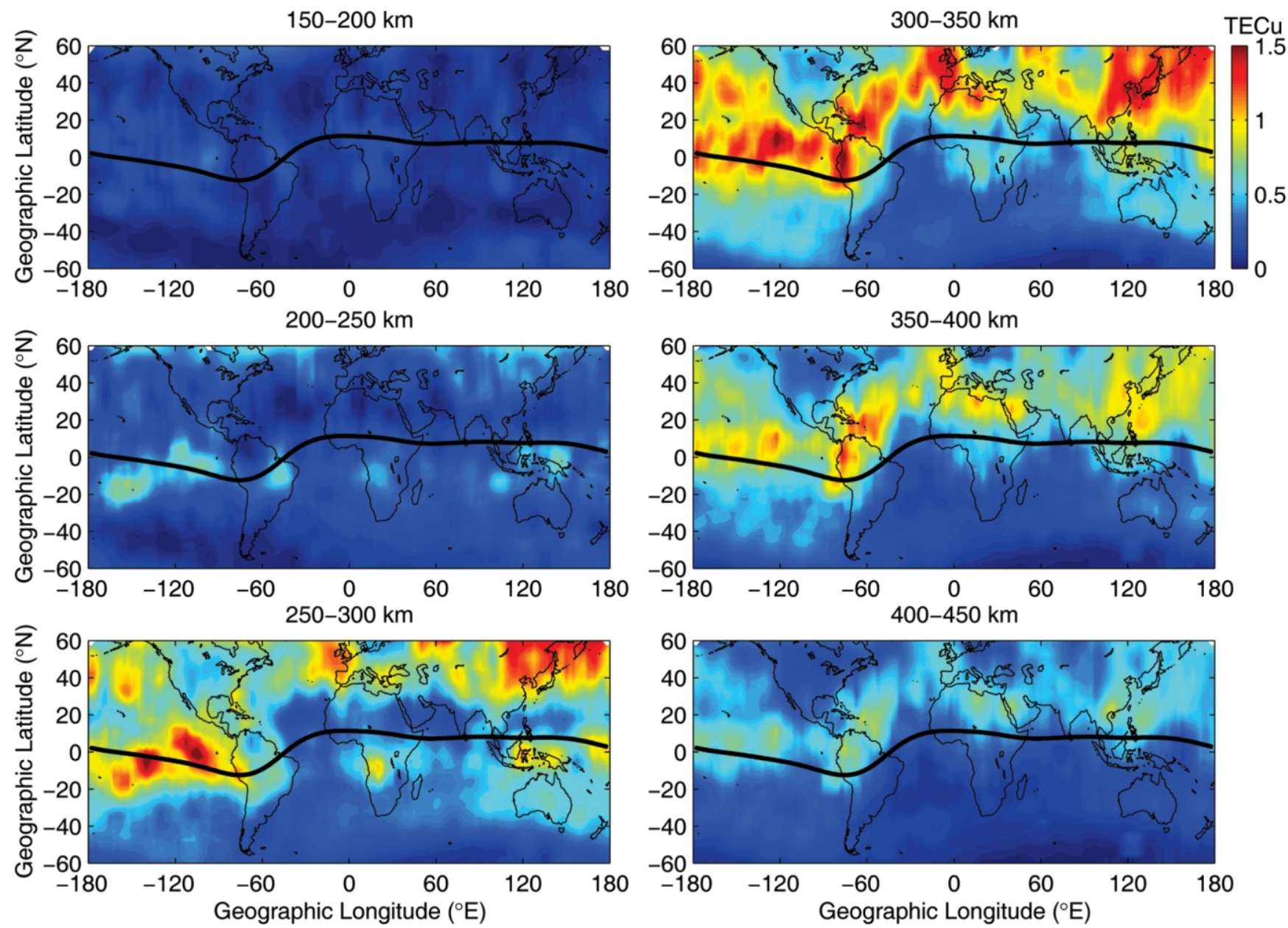

Fig. 3. Global ionosphere electron density maps at a constant local time, 0000 LT, at various altitudes observed by FORMOSAT-3/COSMIC during July - August 2006. Each subplot shows integrated electron content between the $50 \mathrm{~km}$ altitude interval. $1 \mathrm{TECu}=10^{16} \mathrm{electron} \mathrm{m}^{-2}$.

$0^{\circ}$ E geographic longitudes) and at Arabian Sea between India and Middle East $\left(45 \sim 90^{\circ} \mathrm{E}\right.$ geographic longitudes). Both depletion areas are at around $0 \sim 20^{\circ} \mathrm{N}$ geographic latitudes, close to the magnetic equator.

To further examine the variations of the ionospheric electron density structure shown in Figs. 2 and 3, timesequential cross-section electron density distribution at a longitude meridian of $60^{\circ} \mathrm{E}$ geographic longitude is shown in Fig. 4. From Fig. 4, the EIA start to be seen at 0700 LT and becomes stronger and well developed in the southern hemisphere. The northern EIA crest is seen at 1300 LT but still weaker than the southern crest. The asymmetric EIA crest development is likely to be produced by the summer-to-winter neutral wind that brings plasma from summer (northern hemisphere) hemisphere to winter hemisphere (southern hemisphere). This result is consistent with previous regional GPS TEC observation (Tsai et al. 2001), satellite in-situ measurement (Kil et al. 2006), and theoretical modeling work (Lin 2005; Fang et al. 2006). After 1100 LT, the equatorial plasma fountain becomes stronger and thus the northern EIA crest starts to be formed despite the summerto-winter wind still exists. These unprecedented detailed ionospheric images are constructed by dense and threedimensional global observations of F3/C. Detailed discussion of the bi-hourly images can be found at Lin et al. (2007b). Figure 4 also shows that the electron density in the southern hemisphere reduced significantly after 1700 LT due to smaller solar zenith angle and decreasing photoionization. The EIA structure collapsed at 1900 LT and the region of higher electron density moves northward where sun light still exists. At 2100 and 2300 LT, the region of higher electron density spanned around $15 \sim 45^{\circ} \mathrm{N}$ magnetic latitudes, roughly corresponding to $25 \sim 55^{\circ} \mathrm{N}$ geographic latitudes. The density map at 2300 LT in Fig. 4 shows a depletion density area between $0 \sim 15^{\circ} \mathrm{N}$ magnetic latitudes (at around $10 \sim 25^{\circ} \mathrm{N}$ geographic latitudes), which is similar to the latitudinal location of the depletion zone shown in Fig. 3 between $45 \sim 90^{\circ} \mathrm{E}$ geographic longitudes. The depletion zones shown in both Figs. 3 and 4 indicate consistent observation of this unique ionospheric structure. Many of the pe- 


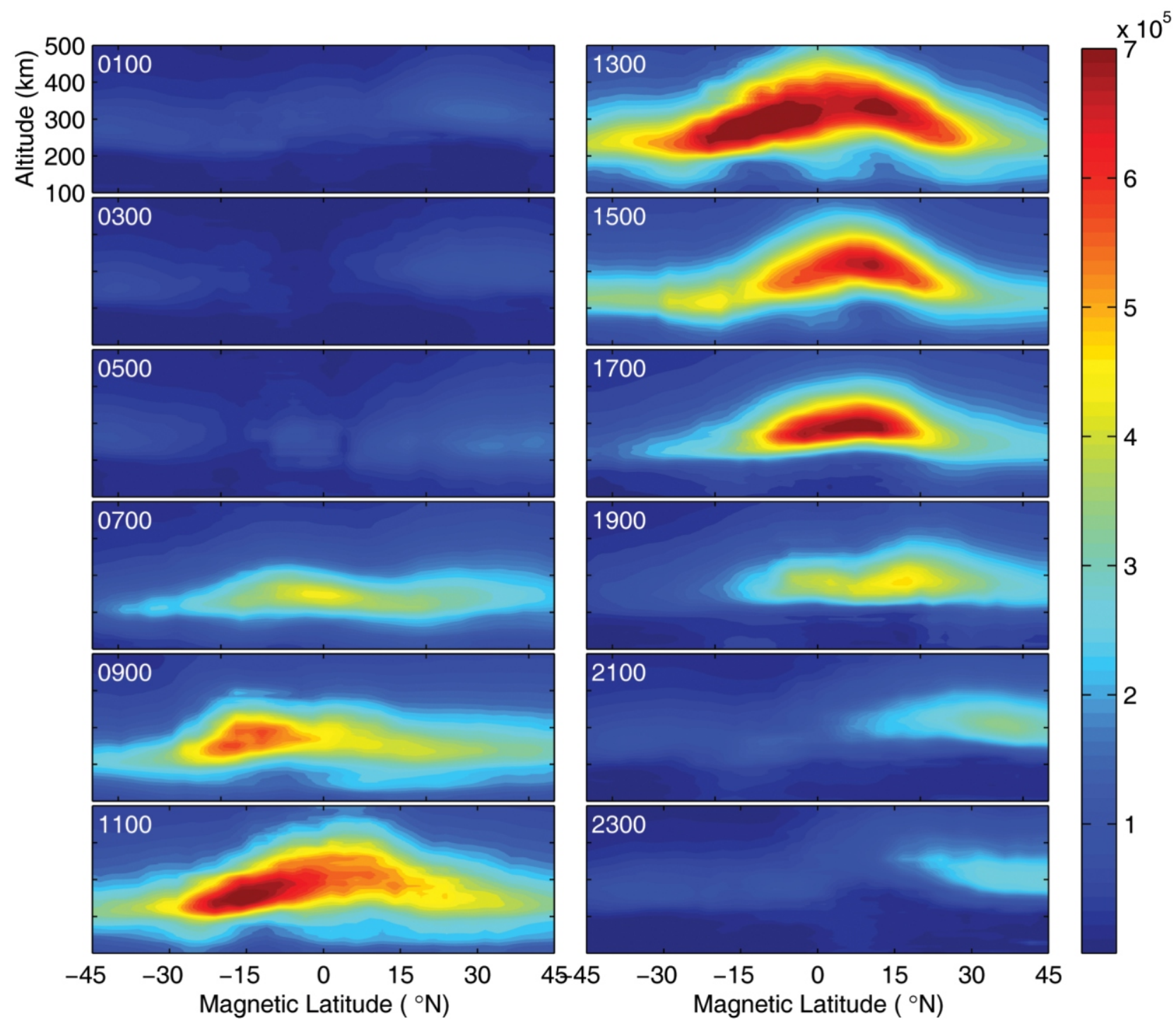

Fig. 4. Time evolution of the ionospheric plasma density structure at the mid- and low-latitude regions at around $60^{\circ} \mathrm{E}$ meridian sector $\left( \pm 15^{\circ}\right.$ longitude intervals). The plasma density structure plot at each time interval is constructed by taking the median of the FORMOSAT-3/COSMIC observations within the two-hour interval during July - August 2006. Time marked in each plot is the central hour of the two-hour interval.

culiar ionospheric plasma structures seen in Figs. 2 and 3 are further shown in Fig. 4, showing great details of the ionospheric variations in different viewing aspects.

\section{LONGITUDINAL STRUCTURE OF THE LOW-LATITUDE AND EQUATORIAL IONOSPHERE}

Recently, ionospheric airglow observations have shown distinct longitudinal structure of the equatorial ionosphere. The longitudinal structure is featured by four enhanced/ stronger equatorial ionization anomaly regions located near to regions of tropical rainstorms. This four-peaked or wavenumber four longitudinal structure of the equatorial ionosphere was first proposed by Sagawa et al. (2005) using far- ultraviolet (FUV) $135.6 \mathrm{~nm}$ emission observation onboard the NASA IMAGE (Imager for Magnetopause-to-Aurora Global Exploration) satellite during equinox-to-early summer of 2002. They found that the feature could not be fully explained by magnetic declination, magnetic field strength, displacement of the magnetic equator from the geographic equator, and empirical electric field and neutral wind models. They proposed that the eastward wavenumber three (E3) diurnal nonmigrating tide, excited from lower atmosphere, propagates upward to the lower ionosphere and subsequently affects the E-region dynamo electric field may be the possible explanation. Later, Immel et al. (2006) and England et al. (2006) superimposed the global distribution of the nighttime equatorial anomaly peaks in the northern hemisphere observed by the IMAGE FUV and the E3 non- 
migrating tide (represented in neutral temperature) simulated by the Global Scale Wave Model (Hagan and Forbes 2002, 2003). The surprisingly good match of the four enhanced plasma regions and the four-maximum-temperature tidal signatures supports the hypothesis made by Sagawa et al. (2005). The E3 diurnal nonmigrating tide is excited by latent heat release in the troposphere. When viewing zonal wind and temperature amplitude from the global constant local time perspective (or sun-synchronize orbit), the E3 diurnal nonmigrating tide exhibits four lower thermospheric or E-region maxima (e.g., Oberheide et al. 2003; Forbes et al. 2006) at the same longitude locations of the four strong equatorial ionization anomaly (EIA) zones (e.g., England et al. 2006; Immel et al. 2006).

Although above observations have provided some evidence to support the hypothesis of modulating the E-region dynamo by atmospheric tides, those observations, however, are only limited to the nighttime period when the E-region has almost disappeared. Thus, it is extremely important to demonstrate that the four-peaked longitudinal structure exists during daytime when the E-region exist with strong interactions with F-region, in order to support the hypothesis made by previous studies. With the availability of the global 3-D ionospheric observations in both daytime and nighttime, the FORMOSAT-3/COSMIC is, therefore, the ideal suite of instruments to monitor vertical electron density of the four-peaked longitudinal structures and to further under- stand the possible coupling process between the equatorial ionosphere and the nonmigrating tides of tropospheric origin, or other possible mechanisms. Figure 5 shows the global ionospheric map at constant local times of 1400 - 1600 and $2000-2200$ LT. The constant local time maps are constructed using similar method of Figs. 2 and 3 by binning measurements from two months (e.g., September - October 2006) of occultation data in a two-hour interval (or hourly), and taking the median value of observations located in the same $2.5^{\circ}-2.5^{\circ}-1 \mathrm{~km}$ (longitude-latitudealtitude) grid.

The four-peaked structure is most prominent at 1400 1600 LT during daytime and at 2000 - 2200 LT at night. It is noted here that the altitudinal range of the daytime fourpeaked structure varies at different local time. In general, the four-peaked structure appeared at higher altitude during daytime than at night. A possible explanation may be that the photoionization exists during daytime and the source of the plasma enrichment in the equatorial ionosphere is then not only relying on the equatorial plasma fountain effect. At higher altitudes, due to rapid decrease of the neutral atomic oxygen, the photoionization reduced significantly and the plasma fountain effect dominated resulting in clearer fourpeaked longitudinal structure at higher altitude during daytime. Two important results are shown in Fig. 5. One of which is the observation of the four-peaked structure in ionospheric electron density. It is the first time that the

(a)

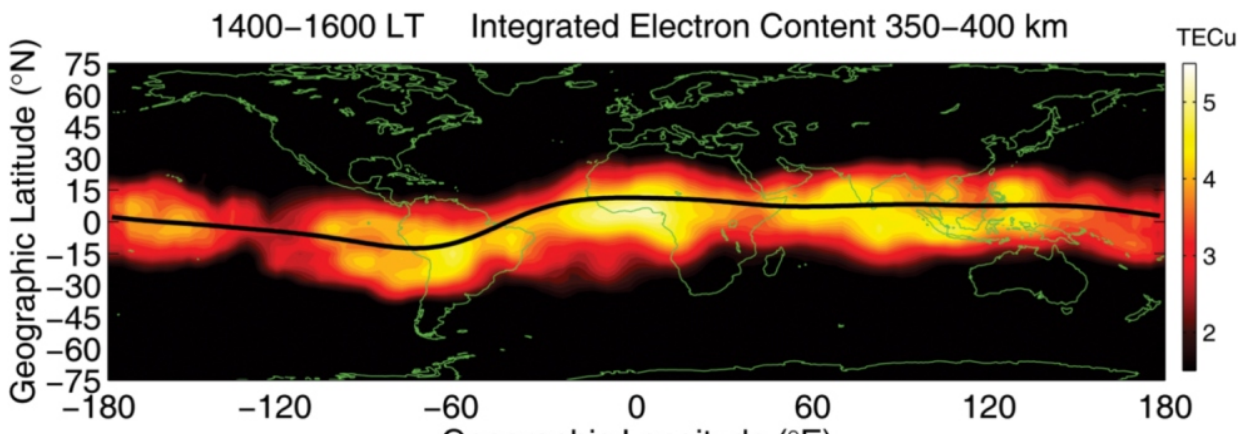

(b)

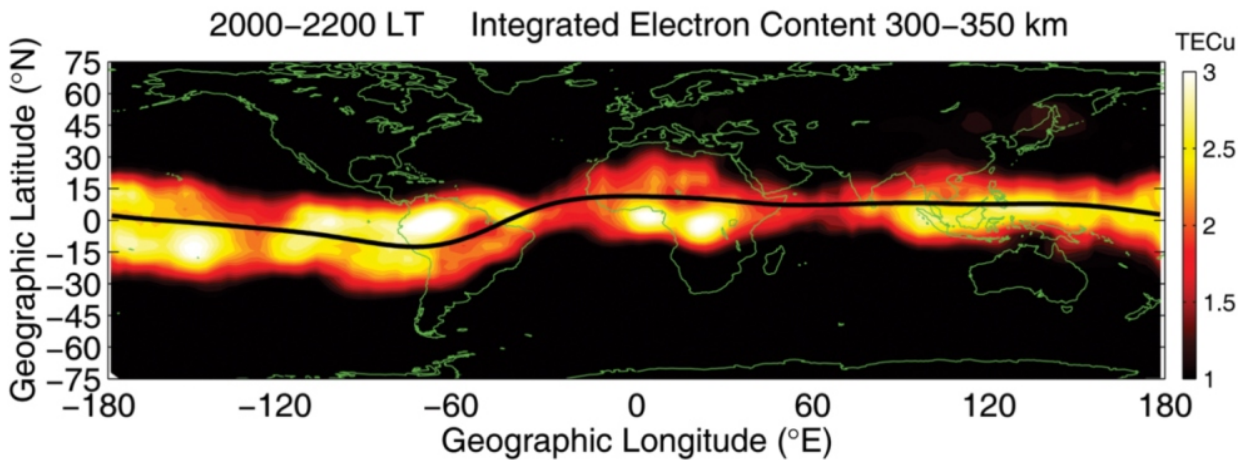

Fig. 5. Ionospheric electron content integrated between (a) 350 - $400 \mathrm{~km}$ altitude range at 1400 - $1600 \mathrm{LT}$ and between (b) 300 - $350 \mathrm{~km}$ altitude range at $2000-2200 \mathrm{LT}$ around the September Equinox, 2006. $1 \mathrm{TECu}=10^{16}$ electron $\mathrm{m}^{-2}$. 
longitudinal structure of the electron density at various altitudes is observed. The airglow observations depend on the layer thickness, absorption, and volume emission rate, while F3/C directly observes variations in electron density. With this advantage, we are able to locate the altitude range where the structure starts to be pronounced. Lin et al. (2007c) has demonstrated that the structure appeared mainly above $250 \mathrm{~km}$ altitude, around F-region height, at 2000 - 2200 LT indicating that the structure is the F-region feature and results from F-region process. The second important result is to demonstrate that the four-peaked structure exists not only at night but also during daytime when the E-region exists and interacts with the F-region strongly. Lin et al. (2007a) showed that the four-peaked structure starts to form at around $0800-1000 \mathrm{LT}$ and becomes prominent at between $1200-1600$ LT. The two important results indicate that the F3/C observations are consistent with the hypothesis of that the four-peaked longitudinal structure is caused by longitudinal variation of the plasma fountain strength modulated by the E3 nonmigrating tide.

\section{SUMMARY}

This paper addresses the importance and advantage of the $\mathrm{F} 3 / \mathrm{C}$ in observing global three-dimensional ionospheric structure with six microsatellites performing radio occultation. With the aid of the ionospheric images, ionospheric variations and dynamics due to seasonal effects and the atmospheric-ionospheric coupling processes can be further understood. Movements of the EIA crests show a clear seasonal asymmetry, which may result from interactions between the summer-to-winter neutral wind and the plasma fountain effect. Observing the four-peaked longitudinal structure in both daytime and nighttime with altitude specification provides significant evidence to support the physical hypothesis of the structure.

Acknowledgements CHL thanks Dr. C. S. Lin of the AFRL for helpful discussions and suggestions and Dr. N. Y. Chen for reviewing the manuscript before submission. CHL and CCH thank the FORMOSAT-3/COSMIC orbital operation team in the National Space Organization (NSPO) for operating the satellite constellation to the mission orbit. This work is partially supported by the Taiwan National Science Council under NSC 96-2111-M-492-001 and by NSPO under 96-NSPO(B)-SP-FA07-03(A) and 97NSPO(B)-SP-FA07-03(E). Part of this work was carried out when CHL was in NSPO. The authors thank the two anonymous reviewers for their constructive suggestions.

\section{REFERENCES}

Anderson, D. N., 1973: A theoretical study of the ionospheric F-region equatorial anomaly, I, Theory. Planet. Space Sci.,
21, 409-419, doi: 10.1016/0032-0633(73)90040-8. [Link] Appleton, E. V., 1946: Two anomalies in the ionosphere. $\mathrm{Na}$ ture, 157, 691, doi: 10.1038/157691a0.

Balan, N. and G. J. Bailey, 1995: Equatorial plasma fountain and its effects: Possibility of an additional layer. J. Geophys. Res., 100, 21421-21432, doi: 10.1029/95JA01555. [Link]

Balan, N., G. J. Bailey, M. A. Abdu, K. I. Oyama, P. G. Richards, J. MacDougall, and I. S. Batista, 1997: Equatorial plasma fountain and its effects over three locations: Evidence for an additional layer, the F3 layer. J. Geophys. Res., 102, 2047-2056, doi: 10.1029/95JA02639. [Link]

Cheng, C. Z., Y. H. Kuo, R. A. Anthes, and L. Wu, 2006: Satellite constellation monitors global and space weather. EOS Trans. $A G U, 87$, doi: 10.1029/2006EO170003. [Link]

Duncan, R. A., 1960: The equatorial $F$ region of the ionosphere. J. Atmos. Terr. Phys., 18, 89, doi: 10.1016/0021-9169(60) 90081-7. [Link]

England, S. L., T. J. Immel, E. Sagawa, S. B. Henderson, M. E. Hagan, S. B. Mende, H. U. Frey, C. M. Swenson, and L. J. Paxton, 2006: Effect of atmospheric tides on the morphology of the quiet time, postsunset equatorial ionospheric anomaly. J. Geophys. Res., 111, A10S19, doi: 10.1029/ 2006JA011795. [Link]

Fang, T. W., J. Y. Liu, A. D. Richmond, P. Y. Chang, and C. H. Lin, 2006: Seasonal variation of the global ionosphere. EOS Trans. AGU, 87, Fall Meet. Suppl., Abstract SA33B0272.

Fesen, C. G., G. Growley, and R. G. Roble, 1989: Ionospheric effects at low latitudes during the March 22, 1979, geomagnetic storm. J. Geophys. Res., 94, 5405-5417, doi: 10.1029/JA094iA05p05405. [Link]

Fjeldbo, G., A. J. Kliore, and V. R. Eshleman, 1971: The neutral atmosphere of Venus as studied with the mariner $\mathrm{V}$ radio occultation experiments. Astron. J., 76, 123 pp, doi: 10.1086/111096. [Link]

Forbes, J. M., J. Russell, S. Miyahara, X. Zhang, S. Palo, M. Mlynczak, C. J. Mertens, and M. E. Hagan, 2006: Troposphere-thermosphere tidal coupling as measured by the SABER instrument on TIMED during July - September 2002. J. Geophys. Res., 111, A10S06, doi: 10.1029/2005 JA011492. [Link]

Hagan, M. E. and J. M. Forbes, 2002: Migrating and nonmigrating diurnal tides in the middle and upper atmosphere excited by tropospheric latent heat release. J. Geophys. Res., 107, 4754, doi: 10.1029/2001JD001236. [Link]

Hagan, M. E. and J. M. Forbes, 2003: Migrating and nonmigrating semidiurnal tides in the upper atmosphere excited by tropospheric latent heat release. J. Geophys. Res., 108, 1062, doi: 10.1029/2002JA009466. [Link]

Hajj, G. A. and L. J. Romans, 1998: Ionospheric electron density profiles obtained with the global positioning system: Results from the GPS/MET experiment. Radio Sci., 33, 175-190, doi: 10.1029/97RS03183. [Link]

Hajj, G. A., L. C. Lee, X. Pi, L. J. Romans, W. S. Schreiner, P. R. 
Straus, and C. M. Wang, 2000: COSMIC GPS ionospheric sensing and space weather. Terr. Atmos. Ocean. Sci., 11, 235-273.

Hanson, W. B. and R. J. Moffett, 1966: Ionization transport effects in the equatorial $F$ region. J. Geophys. Res., 71, 5559.

Immel, T. J., E. Sagawa, S. L. England, S. B. Henderson, M. E. Hagan, S. B. Mende, H. U. Frey, C. M. Swenson, and L. J. Paxton, 2006: Control of equatorial ionospheric morphology by atmospheric tides. Geophys. Res. Lett., 33, L15108, doi: 10.1029/2006GL026161. [Link]

Kil, H., R. DeMajistre, L. J. Paxton, and Y. Zhang, 2006: Nighttime F-region morphology in the low and middle latitudes seen from DMSP F15 and TIMED/GUVI. J. Atmos. Sol.Terr. Phys., 68, 1672, doi: 10.1016/j.jastp.2006.05.024. [Link]

Komjathy, A., L. Sparks, B. D. Wilson, and A. J. Mannucci, 2005: Automated daily processing of more than 1000 ground-based GPS receivers for studying intense ionospheric storms. Radio Sci., 40, RS6006, doi: 10.1029/ 2005RS003279. [Link]

Lin, C. H., 2005: Low-Latitude Ionosphere Variations during Magnetic Disturbances. Ph.D. Thesis, National Centra Univ., Taiwan, 56-75.

Lin, C. H., C. C. Hsiao, J. Y. Liu, and C. H. Liu, 2007a: Longitudinal structure of the equatorial ionosphere: Time evolutions of the four-peaked EIA structures. J. Geophys. Res., 112, A12305, doi: 10.1029/2007JA012455. [Link]

Lin, C. H., J. Y. Liu, T. W. Fang, P. Y. Chang, H. F. Tsai, C. H. Chen, and C. C. Hsiao, 2007b: Motions of the equatorial ionization anomaly crests imaged by FORMOSAT-3/ COSMIC. Geophys. Res. Lett., 34, L19101, doi: 10.1029/ 2007GL030741. [Link]

Lin, C. H., W. B. Wang, M. E. Hagan, C. C. Hsiao, T. J. Immel, M. L. Hsu, J. Y. Liu, L. J. Paxton, T. W. Fang, and C. H. Liu, 2007c: Plausible effect of atmospheric tides on the equatorial ionosphere observed by the FORMOSAT-3/ COSMIC: Three-dimensional electron density structures. Geophys. Res. Lett, 34, L11112, doi: 10.1029/2007GL
029265. [Link]

Mannucci, A. J., B. D. Wilson, D. N. Yuan, C. H. Ho, U. J. Lindqwister, and T. F. Runge, 1998: A global mapping technique for GPS-derived ionospheric total electron content measurements. Radio Sci., 33, 565-582, doi: 10.1029/ 97RS02707. [Link]

Mendillo, M. and J. A. Klobuchar, 2006: Total electron content: Synthesis of past storm studies and needed future work. $R a-$ dio Sci., 41, RS5S02, doi: 10.1029/2005RS003394. [Link]

Namba, S., and K. I. Maeda, 1939: Radio Wave Propagation, Corona, Tokyo, $86 \mathrm{pp}$.

Oberheide, J., M. E. Hagan, and R. G. Roble, 2003: Tidal signatures and aliasing in temperature data from slowly precessing satellites. J. Geophys. Res., 108, 1055, doi: 10.1029/2002JA009585. [Link]

Rishbeth, H., 1998: How the thermospheric circulation affects the ionospheric F2-layer. J. Atmos. Sol.-Terr. Phys., 60, 1385-1402, doi: 10.1016/S1364-6826(98)00062-5. [Link]

Rishbeth, H., 2000: The equatorial F-layer: Progress and puzzles. Ann. Geophys., 18, 730-739, doi: 10.1007/s00585000-0730-6. [Link]

Rocken, C., R. Anthes, M. Exner, D. Hunt, S. Sokolovskiy, R. Ware, M. Gorbonov, W. Schreiner, D. Feng, B. Herman, H. Y. Kuo, and X. Zou, 1997: Analysis and validation of GPS/MET data in the neutral atmosphere. J. Geophys. Res., 102, 29849-29866, doi: 10.1029/97JD02400. [Link]

Sagawa, E., T. J. Immel, H. U. Frey, and S. B. Mende, 2005: Longitudinal structure of the equatorial anomaly in the nighttime ionosphere observed by IMAGE/FUV. J. Geophys. Res., 110, A11302, doi: 10.1029/2004JA010848. [Link]

Scherliess, L. and B. G. Fejer, 1999: Radar and satellite global equatorial F region vertical drift model. J. Geophys. Res., 104, 6829-6842, doi: 10.1029/1999JA900025. [Link]

Schreiner, W. S., S. V. Sokolovskiy, C. Rocken, and D. C. Hunt, 1999: Analysis and validation of GPS/MET radio occultation data in the ionosphere. Radio Sci., 34, 949-966, doi: 10.1029/1999RS900034. [Link]

Yunck, T., 2002: An overview of atmospheric radio occultation. J. Global Positioning System, 1, 58-60. 